\title{
Make the Cover Letter Extinct
}

\author{
Jaime A. Teixeira da Silva \\ P. O. Box 7, Miki-cho post office, Ikenobe 3011-2, Kagawa-ken, 761-0799, Japan \\ jaimetex@yahoo.com
}

\section{Doi:10.5901/jesr.2015.v5n2p11}

Traditionally, the cover letter $(\mathrm{CL})$ served as the formal entry point of submission to an academic journal. The $\mathrm{CL}$ was a formal letter, usually on paper with official letter head, full addresses, date and signature, a document that served to indicate the desire of a would-be author that he/she wanted to submit a paper to that journal for possible consideration. Back in the day when there were no online submission systems (OSSs), or e-mails, or even the internet, the formal CL was the only official document that bridged the unknown between an author and an editor upon submission. The CL also served as the bridge to develop trust, and to provide written, signed and dated guarantees of originality. Gradually, as the age of the internet grew, e-mails facilitated and speeded up communication between editors/journals and authors, and as OSSs automated the entire submission system, the need for hard-copy CLs began to disappear. This gradual transition to the open access system also allowed for the system to be more easily abused, since it became easier to be more productive in a less amount of time, without the restrictions imposed by the existence of the hard-copy "on paper" system that had to be submitted by post, an often costly process.

The norm nowadays, whether for traditional print or open access journals, is for a submission to comply with the instructions for authors (IFA) and the ethical policies of that journal. Thus, submission to a journal now almost invariably implies, even if not explicitly written, signed, or dated, that all the norms indicated online or in the IFAs are respected upon submission. This usually includes aspects like ethics, authorship, adherence to stylistic norms, originality and single submission. Such criteria are usually spelt out clearly within most IFAs. In many journals, there is also a requirement to define the author(s) contribution, or to indicate any possible or actual conflicts of interest within the manuscript itself, thus making these declarations within a $\mathrm{CL}$ unnecessary. Finally, whereas previously potential peer reviewers were suggested in the $\mathrm{CL}$, this function now takes place in OSSs. Despite all of these inherent guarantees that exist for many if not most journals, one may still find journals that require a CL for submission, even on OSSs. Why is this?

I claim that in this day and age, in which there are sufficient checks and balances during the OSS, that the $C L$ is simply a waste of time. Scientists are increasingly busy, and within that precious and restricted time frame, even the time required for writing and submitting a $\mathrm{CL}$ can be a waste of energy, effort and time. Based on the current redundant functionality and need of the $\mathrm{CL}, \mathrm{I}$ am calling for it to be scrapped from all submissions to all journals. Unlike a job application, the $\mathrm{CL}$ for submission to an academic journal is no longer necessary, let alone essential. Also, unlike what is claimed in [1, 2], the CL should never be used to "sell" the image of a scientific paper. The abstract and the summary of the paper serve that purpose perfectly, and more than adequately. There is absolutely no need for this marketing-driven mentality associated with the CL. Thus, unlike the claim made in [2], "Strong cover letters not only introduce your manuscript - they offer an important opportunity to convince journal editors to consider your manuscript for publication", CLs should never serve to try and sway or influence the editors in any way. Apparently, unsuspectingly, Blackwell and Martin (2011) highlight the redundancy by stating "However, in essence they should always be the same since they should politely state the Title of the paper, and outline (as in an Abstract) the rationale, objectives, what was done, the findings and the implications of the study, except in a little less detail, since brevity is even more important than in an Abstract. It is also essential to highlight novel aspects of the study (either implicitly or explicitly), as it is in the paper itself. Thus, the ideal covering letter should provide sufficient information for a busy editor to scan very quickly and leave him or her thinking Interesting study! so he or she can pass this verdict to the referees." (pp. 77-78) The submission of a manuscript must be within as neutral a playing field as possible, allowing editors to base their decisions of inclusion or exclusion solely on the content and scientific validity of the manuscript. The "smooth talk" of the CL must never play an influencing role. There are weak, more moderated ideas that question the redundancy of the CL (Jensen 2013), but still showing support for its use in the work environment while failing to address its true and de facto redundancy in the field of science publishing. Perhaps, as Moustafa (2014) states, "the veritable, lasting, impression is that ulterior impression related to the innate value of the candidate (or the manuscript), not from a cover letter that ends in the trash." 


\section{Conflict of Interest Statement}

The author declares that the research for this paper was conducted in the absence of any commercial, financial or other relationships that could be construed as a potential conflict of interest.

\section{References}

[1] http://www.labtestsblog.com/scientific-manuscript-application-importance-cover-letter/

[2] http://www.biosciencewriters.com/Writing-Cover-Letters-for-Scientific-Manuscripts.aspx

Blackwell J, Martin J (2011) Covering letters and referees' objections. In: A Scientific Approach to Scientific Writing, Springer Science+Business Media, LLC, NY, pp 77-94

Jensen DG (2013) The cover letter: relic or still relevant? Science Careers. http://sciencecareers.sciencemag.org/career_magazine/previous_issues/articles/2013_09_18/caredit.a1300202

Moustafa K (2014) Does the cover letter really matter? Science and Engineering Ethics May 2014 http://link.springer.com/article/10.1007/s11948-014-9554-8 